\title{
Evaluating Cross-organizational ERP Requirements Engineering Practices: a Focus Group Study
}

\author{
Maya Daneva \\ Dept. of Computer Science \\ University of Twente \\ Enschede, The Netherlands \\ m.daneva@utwente.nl
}

\author{
Niv Ahituv \\ Faculty of Management \\ Tel Aviv University \\ Tel Aviv, Israel \\ ahituv@post.tau.ac.il
}

\begin{abstract}
This focus group study presents our first validation of practices for engineering the coordination requirements in crossorganizational Enterprise Resource Planning (ERP) projects. The study evaluates 13 practices addressing a variety of coordination aspects crucial to ERP projects. These practices are results in previously published research publications by the first author. The practices are formulated in response to practitioners' needs at ERP adopting organizations. The proposed practices have now reached the stage where we need some independent feedback as to the extent to which they fit the realities of practitioners. We perform this validation by means of a qualitative research approach, namely the focus group method. Current software engineering literature provides few examples of using focus groups in the evaluation of good software development practices. Because of this, providing reflections on our focus-group-based validation experiences will be of value to both the research community and practitioners.
\end{abstract}

Keywords-requirements engineering, enterprise resource planning, empirical software engineering

\section{INTRODUCTION}

Requirements engineering for ERP projects gets increasingly more difficult and riskier in the $21^{\text {st }}$ century due to the changing nature of the businesses adopting ERP solutions and the changing nature of the ERP packages made available by ERP vendors. Businesses are getting increasingly more involved in what is called 'value webs', or 'business networks', which is a collaboration of profit-and-lost responsible business entities with the mission to deliver a product or a service that satisfies a client's need. For example, the business network of WalMart Stores Inc. uses an ERP-enabled value web to collaborate - by means of a global ERP coordination support system, with a large number of non-U.S. companies and gives them direct access to the American market [1].

To catch up with the ERP adopting organizations' needs for collaboration and coordination, ERP vendors brought to the marketplace a new generation of packages that come with a set of pre-defined coordination mechanisms, ready for configuration to the specific context of the business network which the package will support [15]. In the earlier research by the first author [1,2], we investigated the questions of (i) how to engineer the requirements for cross-organizational coordination in ERP projects [1] and (ii) what represents good practices of engineering the coordination requirements for shared ERP solutions [2]. We found that the coordination among companies in a value network takes place in four different levels of complexity. In regard to these levels, we also proposed $13 \mathrm{RE}$ practices along with an early indication of the benefits one can expect of introducing each RE practice in an organization. While in our earlier publications [1,2], we reported on our motivation to search for the RE practices and on our research process that helped us derive them, in this paper, we present the practices while focusing on the need to evaluate them. Specifically, our goal is to carry out an initial evaluation of the practices based on ERP practitioners' feedback. This paper provides a detailed account on how we used an asynchronous online focus group approach to do this. The present evaluation study represents the first step out of the many steps we planned to empirically evaluate the RE practices.

The paper is structured as follows: Section II provides the RE practices which we plan to evaluate. Section III describes the focus group research method that we adopted for this study. Section IV presents the application of this method. Section V discusses the results and Section VI is about our reflection of our experiences. Section VII concludes the paper.

\section{BACKGROUND ON THE RE PRACTICES SUBJECTED TO EVALUATION}

This section presents the object of investigation in this study, namely the practices for engineering the coordination requirements in an ERP project. Our earlier empirical study identified 13 practices. We also found evidence suggesting that these practices are not applicable to all ERP adopting organizations and we used the notion of 'coordination complexity level' to indicate which practice is suitable for what ERP coordination context in an organization. We call 'coordination complexity' the extent to which a company participates in a business network. This term is based on Champy's analysis of the ways in which companies' participate in networks [3]. In [2], we defined four levels of coordination complexity, each reflecting how extensively a company lets other companies collaborate in and share its own business processes.

Each level of coordination complexity is characterized by types of partner companies involved, unique cross- 
organizational coordination goals, areas of sharing, and coordination mechanisms used. The notion of coordination level, thus, reflects the understanding that the more diverse the business partners are in a value network, and the larger their number, the greater the coordination challenge [2,3]. Consequently, Level 1 represents the least challenging coordination scenarios and the least complex alignment requirements, while Levels 2,3 , and 4 successively progress to more and more challenging coordination processes and more complex alignment requirements. The levels are defined as follows:

- At Level 1, a company aligns its own processes. An ERPadopter at Level 1 has the goal to improve internal coordination among departments.

- At Level 2 an organization aligns its processes along with the processes of one other type of organization. A Level 2 ERP-adopter's goal is to improve coordination with this type of organization, namely either a client, or a supplier [3].

- At Level 3, a company aligns its processes along with the processes of two other types of organizations. A Level 3
ERP-adopter's goal is to improve coordination with two more company types, e.g. suppliers as well as clients.

- At Level 4, a company aligns its processes with the processes of organizations of three other types. A Level 4 ERP-adopter works to improve coordination with three other types of organizations. At this level, it is not uncommon for these networks to change the coordination mechanisms in an entire business sector.

To help companies make a choice on which out of the 13 $\mathrm{RE}$ practices to use in their ERP project, we associated each practice to one or more of the above-mentioned levels of coordination complexity. So, we assume that if ERP adopting organization is aware of its level of coordination complexity, it would be possible to pick up those RE practices suitable for a project which targets to achieve that particular level of coordination. The RE practices and their relevant levels of coordination complexity are presented in Table I. We make the note that there is no one-to-one mapping between the practices and the levels. This means, that a practice can be associated to more than one levels of coordination complexity.

TABLE I. THE RE PRACTICES TO BE EVALUATED

\begin{tabular}{|l|c|}
\hline \multicolumn{1}{|c|}{ RE Practice } & $\begin{array}{c}\text { Relevant Complexity } \\
\text { Level for Organizations to } \\
\text { use the practice }\end{array}$ \\
$2,3,4$ \\
\hline P1. Define how work gets divided between partner companies & 2,3 \\
\hline $\begin{array}{l}\text { P2. For each network partner, document data, processes, and communication channels to be shared and with } \\
\text { whom }\end{array}$ & 4 \\
\hline P3. Document values and goals to be shared and with whom & 4 \\
\hline $\begin{array}{l}\text { P4. Collect enough knowledge about the ERP supported internal processes before starting for cooperating ERP } \\
\text { scenarios }\end{array}$ & 3 \\
\hline $\begin{array}{l}\text { P5. Document what data separately kept applications of partners' companies will share via interfaces to a } \\
\text { common ERP system }\end{array}$ & 4 \\
\hline P6. Align what is shared to what is kept separate & 3,4 \\
\hline P7. Discover and document the market-making mechanisms and common learning models for partners to share & 3 \\
\hline P8. Understand how ERP-supported coordination mechanisms will be used & $2,3,4$ \\
\hline P9. Assess compatibility of partner companies' values and beliefs & $2,3,4$ \\
\hline P10. Make a business coordination model & $2,3,4$ \\
\hline P11. Map the business coordination model into a set of ERP-supported coordination mechanisms & $2,3,4$ \\
\hline P12. Use the reference architecture for the package provided by the ERP vendor & $2,3,4$ \\
\hline P13. Validate coordination models and their execution & \\
\hline
\end{tabular}

\section{THE FOCUS GROUP RESEARCH METHOD}

Generally, a focus group is a group discussion on a given topic, which is monitored, facilitated and recorded by a researcher. It is a way to better understand how people think about an issue, a practice, a product or a service. In essence, the researcher provides the focus of the discussion, and the data comes from the group interaction. As the interaction is at the heart of the focus group method, the researcher is primarily interested in how experts react to each other's statements and points of view, how they build bridges between their different perspectives, and how they build up shared understanding during the discussion. As a qualitative research technique, focus groups can serve the purpose of both exploration and confirmation studies [4,5]. The key steps in a focus-groupbased research process include the following: (1) defining the research questions related to a research problem, (2) planning the focus group session(s), (3) selecting focus group participants, (4) executing the session(s), (5) data analysis and (6) reporting of results. In Section IV, we present the way in which we implemented these steps in our specific settings.

While the focus group method is broadly used in academic business research, in software engineering, the use of focus groups as an empirical research tool has been only recently discussed [6]. These researchers have also published three focus groups studies on requirements engineering topics $[7,8]$. 
We must note that these authors are among the very few who have ever used the focus group research method in the field of $\mathrm{RE}[8]$.

\section{THE APPLICATION OF THE FOCUS GROUP APPROACH}

\section{A. Research Questions}

The purpose of our focus group study is to evaluate - from the perspective of ERP practitioners, the 13 practices and their association to specific complexity levels. Our plan also includes the evaluation of our focus group experiences to understand the limitations of this early validation study itself.

Our focus group study represents an early assessment exercise in which we set out to clarify two questions:

Question 1: Is what we think to be a good crossorganizational ERP RE practice something that ERP architects observe in their project realities? and

Question 2: If architects do observe a practice, then which complexity level would they put it at?

To answer these questions, we selected the focus group research method because of the following reasons: (1) it is suitable technique for an inquiry like ours, e.g. obtaining initial feedback on new concepts and helping clarify findings that resulted from using other methods, and (2) it is well-known for its cost-effectiveness [14], which was essential in this first validity evaluation, as we needed to collect a concentrated set of observations in a short time span.

More specifically, our plan was to use an online asynchronous focus group $[6,7,9,10,11]$. An online focus group is a focus group organized by using internet resources. We selected the online asynchronous form of focus group because: (i) it is extremely useful when the participants are located in multiple time zones and it is difficult to coordinate a time for geographically far-flung focus group members to participate synchronously, (ii) it provides ready-to-use transcribed data, (iii) it is flexible so that our focus group members sitting in various time zones could contribute at their most convenient time, (iv) it encourages candid interchanges and reduces issues of interviewer's effect as focus group members can not "see" each other, and (v) it allows responses that are usually lengthier and more measured than in a synchronous mode [10].

\section{B. Focus Group Planning}

The planning steps in our focus group study implemented the guidelines proposed by the methodologists [4,5,9,10,11]. Our research questions (stated in the previous section) drove our choices in composing the focus group. We conducted it with practising ERP architects from companies who were interested in exploring similar questions from their companies' perspectives. Our focus group plan included 18 ERP solution architects from four telecommunications services providers, two financial service companies, two retail businesses, and one real estate corporation. We deployed a purposive sampling approach to selecting these focus group participants. The focus group members were selected because (i) they had a characteristic in common, which pertains to the topic of the focus group and (ii) they had the potential to offer information- rich experiences. We make the note that focus groups do not gather to vote or to reach consensus (see [5], p. 4). The intent is to promote self-disclosure and that is what we were after in this study. According to [5], the research procedure we planned to implement is known as 'a participatory focus group'. It collects data through group interaction of people with various backgrounds but with common professional values and common roles in which they execute their professional duties. We also make the note that according to focus group research methodologists [4,5], focus groups are not used to provide a statistically generalizable results applicable to all people similar to the practitioners in a specific study. Therefore, in this study we will adopt - based on the methodologists' recommendations, the criterion of transferability as a useful measure of validity. Transferability asks for whether the results are presented in a way that allows other researchers to evaluate whether the findings apply to their research context.

All 18 ERP architects had the following characteristics:

- They all were in charge of cross-organizational projects that had stakeholders and users at locations distributed in at least four Canadian provinces, namely Quebec, Ontario, Alberta and British Columbia.

- Each architect (i) had at least 6 years of experience in cross-organizational ERP RE, (ii) has been familiar with cross-organizational coordination issues, and (iii) has done proposals to improve his/her company's ERP RE process.

- 13 architects had experience with the SAP's ERP package only. One architect had experience in Oracle only. Two architects had experience with SAP and Peoplesoft, and other two - with SAP and Oracle.

- Five architects were working in Coordination Complexity Level 2 organizations, eleven architects were employed at Level 3 ERP adopters, and two architects were working for Level 4 ERP adopters.

All architects were known to the first author, as she had worked with them on a professional basis between 1995 and 2004. As Krueger and Casey [4] recommend, the moderator (in this case, the researcher) "should be similar to the respondents", meaning he/she comes from the same population. Using purposive sampling, the first author chose the focus group members, based on her knowledge about their typicality. The author chose them among a large group of colleagues based on her judgment whether they meet the requirement to be the professionals who have "the greatest amount of insights on the topic" (as Krueger and Casey say [4]).

\section{Process Execution}

The focus group members were contacted on a personal basis by the author using e-mail. Before opening the discussion, the first author provided the background of this research study and presented the 13 practices as a checklist. The focus group members, then, worked in two stages, dealing with one research question at each stage. This was to ensure 
that the group members are not overwhelmed with a long list of inquiries at the start of the process.

In the execution of the focus group process, the first author served as a moderator. Her responsibility was to review the feedback by the participants, to probe deeper when necessary, and to paraphrase participants' points to make sure misunderstandings were avoided. This researcher made sure everyone had a chance to express themselves, though without pressurizing any expert to write when they were not willing to do so.

Once the data was collected, preliminary analysis of the data took place immediately. The information content was sorted in a way that made sense in relation to the two research questions (Sect 4.2.). We describe the data analysis in more detail in the next section.

\section{RESUlTS FROM THE TWO STAGES OF FOCUS-GROUP INTERACTION}

\section{A. Stage 1}

In the first stage, the architects were asked to review the checklists and mark those practices which they either personally used or witnessed someone else on their RE team using it in the early stage of their ERP projects. Their responses are summarized in Table II. For each practice, we report the number of architects who observed it at least once in real-life settings. Table II indicates that 12 out of 13 practices make sense for practitioners and were actually observed in real-life projects. One practice (P7 in Table II) was not observed at all but the architects attributed this to the fact that this practice referred to coordination with intermediaries and that no focus group member worked on a project with intermediation businesses.

TABLE II. CROSS-ORGANIZATIONAL ERP RE PRACTICES OBSERVED BY 18 ERP ARCHITECTS

\begin{tabular}{|l|c|}
\hline RE Practice & $\begin{array}{c}\text { Number of architects } \\
\text { observing it }\end{array}$ \\
\hline P1. Define how work gets divided between partner companies & 18 \\
\hline P2. For each network partner, document data, processes, and communication channels to be shared and with whom & 17 \\
\hline P3. Document values and goals to be shared and with whom & 11 \\
\hline $\begin{array}{l}\text { P4. Collect enough knowledge about the ERP supported internal processes before starting for cooperating ERP } \\
\text { scenarios }\end{array}$ & 8 \\
\hline $\begin{array}{l}\text { P5. Document what data separately kept applications of partners' companies will share via interfaces to a common } \\
\text { ERP system }\end{array}$ & 18 \\
\hline P6. Align what is shared to what is kept separate & 18 \\
\hline P7. Discover and document the market-making mechanisms and common learning models for partners to share & 0 \\
\hline P8. Understand how ERP-supported coordination mechanisms will be used & 18 \\
\hline P9. Assess compatibility of partner companies' values and beliefs & 9 \\
\hline P10. Make a business coordination model & 12 \\
\hline P11. Map the business coordination model into a set of ERP-supported coordination mechanisms & 6 \\
\hline P12. Use the reference architecture for the package provided by the ERP vendor & 18 \\
\hline P13. Validate coordination models and their execution & 10 \\
\hline
\end{tabular}

\section{B. Stage 2}

In the second stage, we excluded the practice which no one observed (this is P7). We sorted randomly the list of 12 remaining practices and asked the architects to position them in the four coordination complexity levels. We, then, compared how the architects associated the practices to the levels and how we (the researchers) did it (Table III). For each practice, we assessed its mapping to a complexity level by using the percentage occurrences of those architects' rankings which coincide with ours. We adopted a cut-off of $75 \%$ as an acceptable matching level, as recommended in previous validation studies of software engineering practices [12,13]. The data in Table III suggests our mappings matched well with the architects'. Though, we observe four pairs of practices and associated levels, which do not meet the $75 \%$ cut-off level. These are the practices labeled P2, P6, P10, and P12. These practices all refer to the role of modelling in crossorganizational ERP RE. They were subjected to a second review by the architects. The focus group accepted practices P2 and P6 for all complexity levels. This lets us conclude that we need a deeper analysis of these practices at a finer granularity level. We think that these practices are interdependent and may also depend on the choice of other practices. So, we decided to analyze the possible combinations scenarios so that we can clearly get incremental complexity stratification.

The focus group was divided according to three standpoints on positioning practice P10. Nine architects thought that documenting cross-organizational coordination processes should be done by Level 4 ERP adopters because this is a very expensive effort and its pay-offs are much less tangible for Level 2 or 3 organizations. These architects witnessed organizations at lower levels of complexity modeling crossorganizational processes only when the costs for this are split up among the partner companies in the network. 


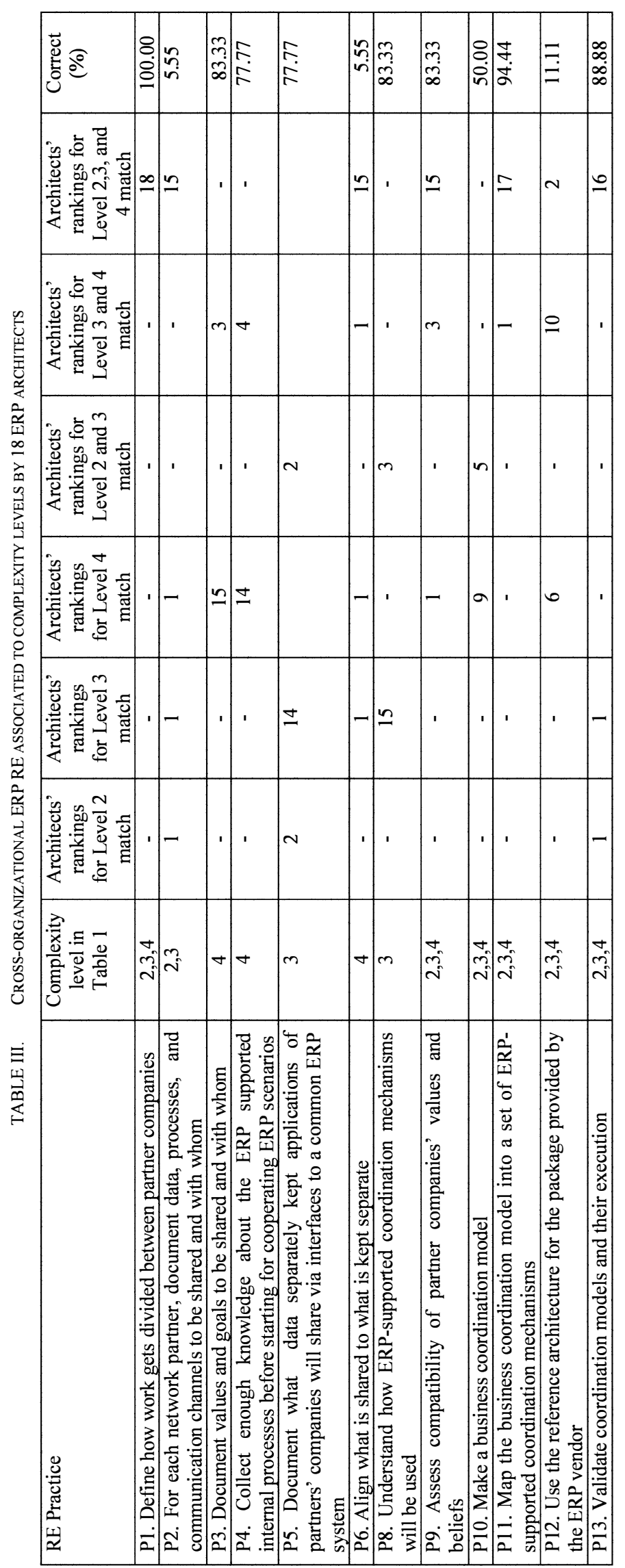


When there is no consensus on the costs, each partner models its own part of the process by using its own preferred modeling technique. Special attention is paid, then, on the inter-companies' process interface points. This is where a process changes its owners and one company hands over the process execution to another. Furthermore, five experts associated practice P10 to Level 2 and Level 3 and argued that modeling prior to architecture design is critical (i) to the remaining implementation stages and (ii) to the architects' ability to connect the cross-organizational solution built now with the one to be built in the future. Four architects stood on the point that modeling is a Level 1 organization's business and claimed that unless an organization does not have an established modeling culture, coordination process modeling would not make much sense, as it may well be perceived as sunk costs from high-level management perspective. We acknowledge that studies in ERP modeling [16] indicated that whenever modeling was done, it turned out to be useful. Modelling the current coordination requirements has key implications in terms of handling requirements for ERP upgrades, system consolidation, and maintenance projects. So, we decided to leave the practice mapped to Levels 2, 3, and 4.

The fourth practice below the $75 \%$ cutoff level was P12. Sixteen architects found P12 as the most controversial activity in ERP project implementation. Six architects associated it to Level 4 ERP adopters and motivated it by stating that reference models are truly beneficial in networks among competitors. Ten architects argued that reference models do not capture shared data control flows and this is a key roadblock in using them efficiently at organizations with a complexity level higher than 2. The author's experience was that reference models were indispensable but the focus group member's knew that the author worked at Level 4 organization. Therefore, the focus group was not convinced at the end of the discussion on where to place this practice. So, we decided to research this question in the future.

\section{Limitations of the study}

We considered the possible threats to validity [4,5] of our results. The major limitation of our focus group setup is that it is centered on a single focus group, which restricts the extent to which generalizations can be drawn from its outcomes. This limitation is off-set by the opportunity to gain a deeper understanding of the association between coordination requirements engineering practices and coordination complexity levels. As Morgan states [5], generalizations are likely appropriate only to professionals in settings similar to the setting of our focus group members. In this respect, we consider the data as "incompletely collected" [5], meaning that what is collected is the experience of the architects. Furthermore, we acknowledge that a plan of at least three focus groups, as methodologists suggest [4,5], would have brought much richer results. However, we could not complete this because of resource constraints. We consider this as our most important issue and, therefore, it tops our agenda for immediate future research. We plan to replicate the focus group in two other countries, the United State and the Netherlands, until we reach saturation, that is, the point when we have collected the range of ideas feedback to us and we are not getting new information $[4,5]$. (We make the note that we did not consider tracking inter-rater agreements because Krueger [4] indicates that focus group members do not gather to come to consensus.)

We also acknowledge the inherent weakness of focus group techniques that they are driven by the researcher, meaning that there is always a residual threat to the accuracy of what focus group members say. However, we believe that in our study, this threat was reduced, because the online focus group was completely transcribed and every single email exchange in the focus group was available for reference purposes.

Furthermore, a validity concern in focus group studies is that the researcher influences the group interaction. However, a study by Morgan [5] indicates that "in reality, there is no hard evidence that the focus groups moderator's impact on the data is any greater than researcher's impact in participant observation or individual interviewing". We also were conscious that the focus group members can influence the data they produce, for example, by means of imbalanced level of participation by the focus group members. We made sure that the focus group was not dominated by a small number of very active participants and that everyone gets a chance to write. This was achieved: (i) by establishing a 'one-message-at-atime' policy, which states that a participant may write only one answer to a message in which there was no pointed question, and (ii) by researcher's approaching individual focus group members any time when she felt participants did not elaborate enough on pointed questions.

\section{REFLECTION ON OUR EXPERIENCE}

Because focus groups have been very rarely reported in empirical RE research [6,7], we thought that reflecting on lessons learnt in carrying out our focus group research and sharing these lessons would be of benefit to other empirical RE and software engineering researchers. So, once the study was over, we approached the participants in order to collect their views on how they felt throughout the focus group. We also reflected on what worked well and why it worked well. In addition, we considered what did not work as we had expected and why. In this reflection process, we constructed mind maps of the experiences in our research process. While this reflection was more qualitative in nature, it allowed for some lessons to crystallize, which we share as follows.

First, we witnessed three important strengths in using online asynchronous focus groups:

Sufficient time for participant's reflection: in our experience, the matter that the focus group members worked asynchronously ensured that the participants could take their time to think and organize their thoughts before responding. We consistently observed that our participants did not diverge from the topics. So, there were much more distilled responses to our questions. The responses also were more in depth, which our participants attributed to the time they took to reflect when formulating their answers. They agreed on that they took sufficient time to think thorough the information they were prepared to share and the example they considered illustrative to make their points. 
Revised role of the moderator: the first author of this paper, who served as a moderator, found that once the environment was setup and the rules of the discussion were established, her role was not interventionist and was actually less directive than originally expected. It was experienced that carefully reading of the participants answers and the insertions of probes and additional clarifying questions did replace the steering role of the face-to-face moderator (that is discussed in the methodological literature on focus group research $[4,5,6,10,11])$.

Absence of hierarchy among the participants: Because the identities of the participants were not known to them, they were prepared to challenge each other's views if they disagreed. Also, the absence of visual cues that indicate dominance of opinions and positions in face-to-face focus groups, seemed to enhance the participants' engagement. In the view of the authors, the idea of being part of a group whose solidarity on particular issue might be at stake, simply did not apply.

Based on our experience, we could also distill one important challenge in running an asynchronous online focus group. It refers to the data analysis of the collected transcripts. If the researcher, who acts as a moderator, wants to or needs to share the transcribed data with other researchers who were not originally involved in the research process, this needs to be handled with special care and time should be allocated for these researchers to catch up with the focus group process and the information in the transcripts. Even for a senior researcher, if not involved in the beginning of the focus group, it could turn-out time consuming to read and re-read the data, so that he/she gains an adequate understanding of it and actively contributes to the data analysis process. The first researcher planed two master students to complete two follow-up projects which would take as input the transcribed data and apply sophisticated coding [5] techniques. However, this idea was abandoned as the junior researchers unfamiliar with qualitative analysis techniques found it very difficult to read and make sense of the information in the long transcripts. To remedy the situation, an experienced senior researcher was involved, which made the research process costlier than originally planned. We, however, think that early planning and estimating of the sharing of knowledge produced through the focus group is key to the data analysis by multiple researchers.

\section{CONCLUSION}

This paper reports on the first step towards evaluating 13 $\mathrm{RE}$ practices. We used an asynchronous online focus group based approach to explore two questions regarding these practices: (1) whether or not what we think to be a good crossorganizational ERP RE practice is also observed by ERP architects in their project realities, and (2) when architects do observe a practice, then which complexity level would they put it at. We found that 12 out of the 13 practices were indeed observed by our focus group members. We also found that the focus group members associated the practices to the levels of coordination complexity, in a way that converged with ours. We also indicated implications of the focus the findings of our group study for future research. Last, we discussed the limitations of our research approach and reflected on its strengths and weaknesses.

\section{ACKNOWLEDGEMENTS}

This research has been financially supported by the Netherlands' Jacquard program for the project "QuadREAD", the NWO's Meervoud program for the project "CARES", and the Joint Project "Evaluation and Selection of Complex Software Systems" between the Institute of Mathematics and Informatics BAS and the Faculty of Management, Tel Aviv University.

\section{REFERENCES}

[1] Daneva M, R.J. Wieringa, A Requirements Engineering Framework for Cross-organizational ERP Systems, Springer Requirement Engineering Journa, 11(3), 2006, pp. 194-204

[2] Daneva M, R.J. Wieringa, Engineering the Coordination Requirements in Cross-organizational ERP Projects: A Package of Good Practices, Proc of IEEE International Conference on Requirements Engineering, 2006

[3] Champy J, X-Engineering the Corporation: the Next Frontier of Business Performance Warner Books, New York, 2002.

[4] Krueger R.A., M.A. Casey, Focus Groups: A Practical Guide for Applied Research, Sage, 2008

[5] Morgan D.L. Focus Group as Qualitative Research Method, $2^{\text {nd }}$ Ed., Qualitative Research Method Series, Vol. 16. Sage, 1997.

[6] Kontio, J., J. Bragge, L. Lehtola, The Focus Group Research Method as an Empirical Toolin Software Engineering, Guide to Advanced Empirical Software Engineering, Ed. F. Schull et all, pp 93-116.

[7] Kontio, J., L. Lehtola, J. Bragge,Using the Focus Group Method in Software Engineering: Obtaining Practitioner and User Experiences, Proc of IEEE International Symposium on Empirical Software Engineering, 2004

[8] Lehtola L., M. Kauppinen, S. Kujala, Requirements Prioritization Challanges in Practice, Proc. of International Conference on Product Focused Software Process Improvement, 2004.

[9] Gaiser, T. Conducting Online Focus Groups: A Methodological Discussion, Social Science Computer Review, 15(2), 1997, pp.135-144

[10] Orgad, S., From Online to Offline and Back: Moving from Online to Oftline Relationships with Research Informants, in Hine, C. (Ed.) Virtual Methods: Issues in Social Research on the Internet, Berg Publishers, Oxford, 2005, pp. 51-65.

[11] Kivits, J. Online Interviewing and the Research Relationship, in Hine, C. (Ed.) Virtual Methods: Issues in Social Research on the Internet, Berg Publishers, Oxford, UK, 2005, pp. 35-49

[12] Krishnan, M.S., Kellner M.I., Measuring Process Consistency: Implications for Reducing Software Defects, IEEE Trans. Software Engineering, 25(6), pp 800-815.

[13] Ramasubbu, N., Kompalli P., Krishnan M.S., Leveraging Global Resources: a Process Maturity Model for Managing Distributed Development, IEEE Software, May/June 2005, pp. 80-86

[14] Kivits, J. Online Interviewing and the Research Relationship, in Hine, C. (Ed.) Virtual Methods: Issues in Social Research on the Internet, Berg Publishers, Oxford, UK, 2005, pp. 35-49.

[15] Ahituv N., Neumann S. \& Zviran M., A System Development Methodology for ERP Systems, Journal of Computer Information Systems, Spring 2002, 56-67

[16] Daneva M, ERP Requirements Engineering Practice: Lessons Learned, IEEE Software, 21(2) 2004, pp. 26-33. 
